\title{
El tranvía de San José: un fantasma de la memoria histórica urbana y del patrimonio de Costa Rica
}

\author{
Isabel Avendaño-Flores ${ }^{1}$
}

Resumen: El artículo trata de dar una visión del tranvía de la ciudad de San José, como parte del patrimonio cultural costarricense, desde la perspectiva de la Geografía Histórica basado en fuentes secundarias, la revisión exhaustiva de periódicos e información del Archivo Nacional de Costa Rica. A partir de ahí se repasan algunos elementos asociados a este medio de transporte que forma parte del patrimonio cultural (inmaterial) del San José de finales del siglo XIX hasta mediados del siglo XX. Si bien el tranvía alude al pasado, y reconociendo la imposibilidad de recrear ese pasado sin alterarlo, su estudio permite re-pensar la ciudad de San José no solo hacia el futuro sino los cambios que se pueden dar sobre el paisaje, las costumbres, la sociedad y la cultura.

Palabras clave: Tranvía; medio de transporte colectivo urbano; patrimonio; cultura

\section{O bonde de San José: \\ um fantasma da memória histórica urbana e do patrimônio de Costa Rica}

Resumo: O artigo trata de dar uma visão do bonde da cidade de São José, como parte do patrimônio cultural, desde a perspectiva da Geografia Histórica baseada em fontes secundárias, a revisão de periódicos e informações exaustivas do Arquivo Nacional da Costa Rica. Estudam-se alguns elementos associados a este meio de transporte que forma parte do patrimônio cultural (imaterial) de San José do século XIX até a metade do século XX. Embora o bonde aluda ao passado, e reconhecendo a impossibilidade de recriar esse passado sem ser alterado, seu estudo permite repensar a cidade de San José não só para o futuro, mas as mudanças na paisagem, nos costumes, na sociedade e na cultura.

Palavras-chave: Bonde; meio de transporte coletivo urbano; patrimônio; cultura

The San José tram:

a ghost of urban historical memory and of Costa Rica heritage

\begin{abstract}
This article tries to give a vision of the tram of the city of San Jose, as part of the Costa Rican cultural heritage, from the perspective of Historical Geography based on secondary sources, the exhaustive review of newspapers and information of the National Archive of Costa Rica. From there, we review some elements associated with this means of transport that is part of the cultural heritage (immaterial), of San Jose from the late nineteenth century to mid-twentieth century. Although the tram alludes to the past and recognizes the impossibility of recreating that past without altering it, its study allows us to rethink the city of San José not only towards the future, but also the changes that can be made to the landscape, customs, society and local culture.
\end{abstract}

Keywords: Tram; urban collective transport; heritage; culture

Recebido: janeiro de 2018. Aceite: março de 2018.

${ }^{1}$ Doutora y docente de la Escuela de Geografia, Universidad de Costa Rica. Email: isabel.avendano@ucr.ac.cr. 


\section{Introducción}

El tranvía eléctrico de San José fue el primer medio de transporte urbano colectivo de Costa Rica. Trasladó mercancías de poco peso y tamaño, pero primordialmente, movilizó viajeros en una época en que las vías de comunicación eran escasas y de mala calidad. A partir de ese momento el tranvía fue sinónimo de progreso, desarrollo, bienestar y expresión de la visión de mundo del San José de fines del siglo XIX y mediados del siglo XX. Como un espejo, traslució las necesidades, el sentir, el carácter socioeconómico e histórico de un pueblo. De igual forma que en otras partes del mundo, el tranvía fue un vehículo amarillo que atravesó con sus rieles a San José y parte de sus alrededores. Hoy día, un falso histórico es la única señal de su existencia; esta réplica se localiza en "Pueblo Antiguo" en el Parque Nacional de Diversiones (Uruca, San José) bajo un contexto de esparcimiento, ocio y recreación.

El tranvía surcó por los puntos cardinales de San José, integró el sistema urbano josefino y propició los primeros procesos de conurbación; sin embargo, su evocación va más allá de haber sido un medio de desplazamiento para convertirse en un espejo de un San José ordenado, con un damero definido, planeado mediante el consenso que generó un arraigado sentido de pertenencia tanto para el ser josefino como para los trabajadores en sus diferentes funciones.

Estas páginas tratan de dar una visión del tranvía de la ciudad de San José, parte del patrimonio cultural costarricense, desde la perspectiva de la Geografía Histórica basado en fuentes secundarias, la revisión exhaustiva de periódicos en la Biblioteca Nacional e información obtenida del Archivo Nacional de Costa Rica. Debido a las abundantes alusiones al tranvía, pero a su vez, a las escasas fuentes dedicadas a este medio de comunicación urbano, este texto reflexiona lo sucedido con el tranvía y se suma a estudios previos como Avendaño-Flores (1991) y Avendaño-Flores (2003).

A partir de ahí se revisan algunos elementos asociados a este medio de transporte que forma parte del patrimonio cultural (inmaterial), del San José de finales del siglo XIX hasta mediados del siglo XX. Si bien el tranvía alude al pasado y reconociendo la imposibilidad de recrear ese pasado sin alterarlo, su estudio permite re-pensar la ciudad de San José no solo hacia el futuro, sino los cambios que se pueden dar sobre el paisaje, las costumbres, la sociedad y la cultura. Se asumen los tipos particulares de patrimonio de la UNESCO: natural, cultural, material, inmaterial o mueble. El caso que interesa, patrimonio cultural, está formado por los bienes culturales que la historia le ha legado a una nación y por aquellos que en el presente se crean y a los que la sociedad les otorga una especial importancia histórica, científica, simbólica o estética y se divide en dos tipos, tangible e intangible. Es la herencia recibida de los antepasados, y que viene a ser el testimonio de su existencia, de su visión de mundo, de sus formas de vida y de su manera de ser, y es también el legado que se deja a las generaciones futuras. El patrimonio tangible es la expresión de las culturas a través de grandes realizaciones materiales y se puede clasificar en mueble e inmueble. Estos elementos son fuente de cohesión social y referente para la creatividad urbana.

El artículo considera también la ruptura de un medio de transporte que fue eficiente $y$ sucumbe ante la barbarie del transporte contaminante y la cultura individualista del automóvil. El tranvía queda derrotado como forma de transporte y espacio interactivo. Cien años después, no se puede rastrear físicamente, sin embargo no se pierden las esperanzas de frente a las crisis del transporte urbano, la posibilidad de reinventar este modo de comunicación de la ciudad y sobre todo, para lograr una mejor convivencia urbana.

\section{San José da un vuelco... 1a modernización disminuye las barreras espaciales}

La historia del tranvía obliga a visualizar la ciudad de San José. El trazado de la Ciudad, sus calles y edificios fueron el reflejo de la vida urbana, el espacio democrático de los pobladores que merece ser estudiado, recuperado y resignificado como derecho de todos sus habitantes. Pero también, porque el pasado determina nuestro futuro. Sin memoria histórica estamos condenados a vivir un eterno presente, la repetición constante del mismo sufrimiento, como Prometeo encadenado (García Bilbao, 2010, como citado en Emmerich, 2011, p. 2).

Las contrataciones de obra nos remiten a los problemas que debió afrontar la empresa representada por Minor C. Keith Meiggs más allá del significado de su presencia en Costa Rica, y que ha sido objeto de múltiples investigaciones. En este caso en particular, en medio de indecisiones, desconfianzas y con múltiples peticiones de los distintos actores para su concesión: permisos, estudios, y discusiones entre la Municipalidad de San José, la Secretaría de Fomento y la Presidencia de la República, éste presentó el proyecto con las mejores "utilidades" para la municipalidad de San José y así, se inicia la instalación del tranvía en el 
año 1885. Catorce años después, el 9 de abril de 1899, atraviesa por primera vez, las calles capitalinas de San José hasta su cierre el 1 de agosto de 1950, cuando hizo su último recorrido para pasar a formar parte del pasado, para salirnos de nuevo hoy al encuentro, en ese "salto de tigre" al que alude Walter Benjamin en su texto sobre el concepto de historia.

Una vez otorgado el proyecto, con empréstitos extranjeros, la "The Electric Light and Corporation" de Londres concretó una de las obras de mayor trascendencia para Costa Rica. El período del implante tranviario coincidió con el auge urbano y la prosperidad poblacional de la ciudad de San José. Para el año 1892, el número de gentes que habitaban el cantón San José casi alcanzó las 20.000 personas. El distrito Hospital concentraba la mayoría de los citadinos $(31 \%)$ y le seguía muy de cerca Catedral. Más tarde, el censo de 1927 da cuenta de que la ciudad estaba habitada por más de 50.000 personas; donde poblacionalmente se consolidaba Hospital, puesto que su peso había aumentado al 37\%. Le secundaba Catedral con el $30 \%$. A escala cantonal, la ciudad conglomeraba el $82 \%$ de la población del cantón primero.

El tranvía eléctrico de San José, como los de otras partes en el mundo, era un vagón amarillo de dimensiones variables y con dos puertas laterales -la trasera y la delantera-. Corría sobre rieles que al final de cada línea se devolvía sin dar vuelta; las dos personas que estaban a cargo del vagón eran las que cambiaban de posición. El vehículo poseía una campana exterior cuyo sonido avisaba y alertaba de su presencia a los caminantes o a los viajeros de las carretas, coches o escasas bicicletas. Al frente había un foco para iluminar en la noche. Fijadas a las paredes laterales, había dos bancas de madera que permitían a las personas estar frente a frente, separadas por una distancia de un metro y medio. Entre las bancas, existía un espacio en el que, agarradas del techo, colgaban dos varillas horizontales con varias correas de cuero para que los viajeros de pie se sostuvieran del vaivén que el vehículo producía mientras hacía su recorrido. Una topografía ondulada como la que posee San José, obligada a que en algunos tramos había que sostenerse con firmeza.

En el año 1886, el inglés Hastings gana la licitación para construir la línea en la ciudad de Cartago. En 1888 se inaugura la primera línea de trenes interurbano de Costa Rica. Estos vagones eran operados por una pequeña locomotora de vapor, sin embargo, solo sobrevive 10 años porque no resistió la competencia del transporte de motor. Diez años después, el 27 de marzo de 1896 se otorga una franquicia para construir un tranvía eléctrico en San José, fue otorgada a un comerciante de café francés llamado Amón
Fasileau Duplantier. El contrato fue transferido al año siguiente al industrial de Nueva York, Minor Cooper Keith, quien había construido la línea de ferrocarril de vapor desde Limón, y luego a la Costa Rica Electric Light \& Traction Co., organizada en Londres en 1898. CREL \& T compró cuatro tranvías eléctricos de Jackson \& Sharp Co. en Wilmington, Delaware, EE. UU. En 1898 (órdenes J \& S 1036-39), los cuatro automóviles, numerados del 1 al 4, llegaron a San José ese año y abrieron el tranvía eléctrico de San José el 9 de abril de 1899 (http://www.tramz.com/cr/cr.html).

Para 1925, la puesta en marcha de los 21 carros que para ese momento recorrían San José, estaba a cargo de aproximadamente 160 empleados. La cultura jerarquizante que caracterizó los proyectos de capital extranjero sobre todo en las explotaciones bananeras, se expresó también en la estructura administrativa. En la cúspide de la empresa estaba el Apoderado, la Administración incluyendo la Superintendencia, hasta llegar a los talleres. Los vehículos estaban a cargo del motorista, quien manejaba de pie la máquina y en la parte de "atrás", se localizaba el conductor, recibiendo los tiquetes de los pasajeros que subían. Asimismo, daba instrucciones y avisaba al motorista con toques de campana cuando debía detenerse o continuar la marcha; marcaba en el "registro" la entrada de los pasajeros; ayudaba a subir y bajar a los usuarios y velaba por resolver situaciones anómalas durante el recorrido. Además, colocaba el "trole" por medio de una cuerda cuando se soltaba del cable conductor de corriente eléctrica que movía el tranvía. Ambos, motorista y conductor vestían traje entero, camisa blanca y un tipo de gorra militar con el escudo de Costa Rica en plateado. Referencias para 1925, indican que se transportaban alrededor de 8.500 personas por mes (Peña, 1999).

La red tranviaria se extendió por un total de $14.326 \mathrm{~m}$ (Fotografía 1). El primer tendido de la línea puesto en funcionamiento y de los últimos en clausurar, cubría la distancia desde la Estación del Atlántico a la boca de la Sabana (1899-1950). Un segundo, partía de este ramal, seguía hacia el sur por calle 20. Con gran movimiento el 1 y 2 de noviembre, denominado "Cementerios", estuvo en circulación por casi una década, de 1900-1908. El tercer ramal anexó el poblado de San Pedro del Mojón (1901-1950) a San José.

Con la idea de enlazar las dos estaciones del ferrocarril, que servía de medio de transporte de personas y de mercadería, y el tranvía por excelencia urbano, desde 1908 se contó con una cuarta línea. Desde la Avenida Central se dirigía por la calle Central hasta desembocar en la Estación del Pacífico; así, recorrió las calles por tres décadas, desde 1908 a 1939. 
Hacia 1909, se cubría el noreste de San José. El tranvía hacia Guadalupe corría por más de $4,5 \mathrm{~km}$ de distancia, transformó cuanto tocaba a su paso. Para que los estudiantes del liceo de Costa Rica y del hoy, Ministerio de Obras Públicas y Transportes (otrora, Ministerio de Fomento) pudieran viajar sin inconvenientes o ir a las festividades de fin de año a Plaza González Víquez, se construyó en 1922, el último ramal; relativamente pronto, cayó en desuso (1937). Finalmente, referencias secundarias escritas dan cuenta de la línea tranviaria rumbo a Rincón de Cubillos, hoy Barrio México. Sin embargo, se desconocen las fechas de inauguración y clausura y aparentemente, iba por la calle 20 y terminaba donde hoy se ubica el Liceo de San José, antes, el rastro o matadero de ganado para proveer a la Ciudad.

Figura 1. Paseo Colón

(Avenida Central de la ciudad de San José, sin fecha).

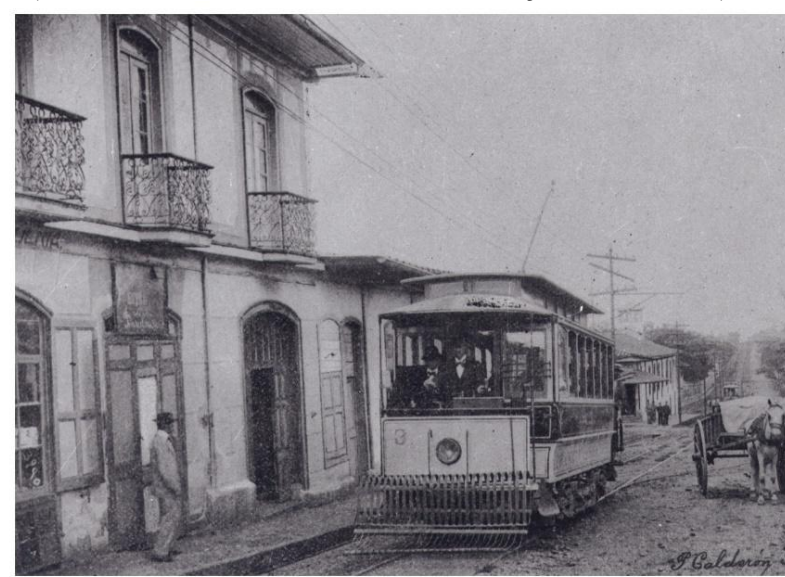

Fuente: Archivo fotográfico del Archivo Nacional de Costa Rica.

El año de 1881, vio funcionar al primer tranvía eléctrico en Berlín y en América Latina, en 1890 en México. Un año antes, el nueve de abril de 1899, los josefinos escucharon por primera vez el sonido de la campanilla del tranvía. Se anunciaba un nuevo servicio de transporte público, pero también, una capital que se ponía a la altura de las más modernas del mundo. Para ese año, Costa Rica era el décimo tercero país de América Latina, en poseer uno. No obstante, la tecnología tranviaria y la ferroviaria impactaron sobremanera la sociedad costarricense. Repercutió en casi todos los ámbitos: social, cultural y político. Para los poblados a los que llegó, generó importantes beneficios económicos que se reflejaron en un mejor nivel y calidad de vida.

Representó el vehículo por excelencia del proyecto liberal, concebido para lograr la integración de los habitantes dentro y alrededor de San José (Figura 2). Y, en este sentido, simbolizó el medio de expresión "del proceso civilizatorio" (Ribero, 1968), como parte de un proceso socio cultural que incidió en todo el desarrollo de la sociedad costarricense de manera progresiva hacia una sociedad moderna, propugnada los grupos políticos liberales frente a los grupos oligárquicos cafetaleros, con quienes disputaban el poder político. En todo caso, significaba un logro de beneficios materiales inmediatos para el sector burgués, que veía en la actividad comercial e industrial un gran potencial. Parafraseando los diálogos en torno al tranvía en las actas de la Municipalidad de San José, sería parte de la infraestructura que permitiría "solventar los permanentes problemas de un comercio expedito con los mercados de ultramar"; acrecentaría el comercio interno y el intercambio de bienes y personas; sería concebida como una obra de interés público tal y como lo declaró el entonces presidente de la República, Bernardo Soto (18861890).

Figura 2. Ciudad de San José, calle 0. A la derecha, la Catedral Metropolitana, 1919.

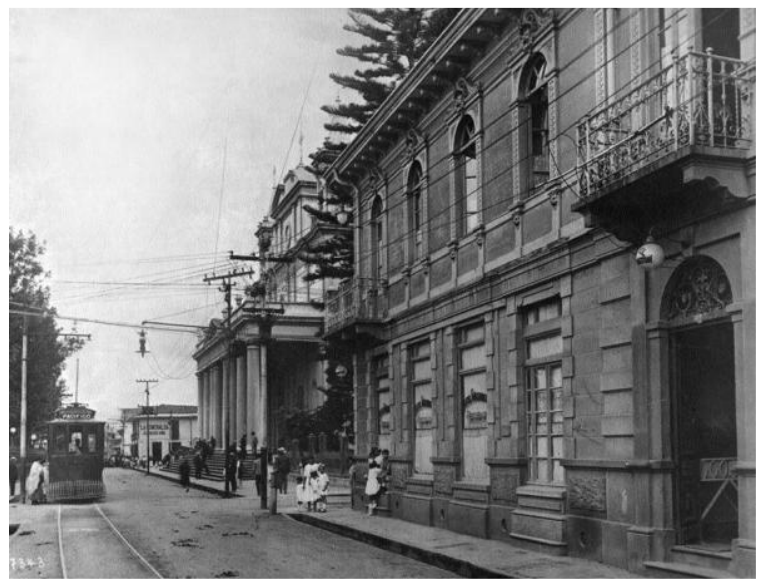

Fuente: Banco Nacional de Costa Rica (1972). Álbum fotográfico de San José. Costa Rica.

El tranvía eléctrico fue parte de un contexto modernizador del espacio costarricense. En las actas municipales se evidencian las diferencias entre concesionarios y receptores. En esta fuente consta la abundante cantidad de peticiones para instalar el alumbrado y la cañería, construir caños, recolectar la basura, regular el ganado o los perros callejeros, ampliar, macadamizar o abrir nuevas calles, y, construir instalaciones recreativas, entre otras solicitudes.

En ese período M. Keith se va consolidando como el máximo accionista de la empresa. Así, el "rey Keith", el "rey del Banano" y su familia eran los poseedores, entre otras empresas, de la "The Costa Rica Electric Light and Traction" (conocida como Compañía del Tranvía), la Compañía Nacional de Electricidad, la Compañía de Teléfonos y la Compañía Nacional Hidroeléctrica o Electriona. 


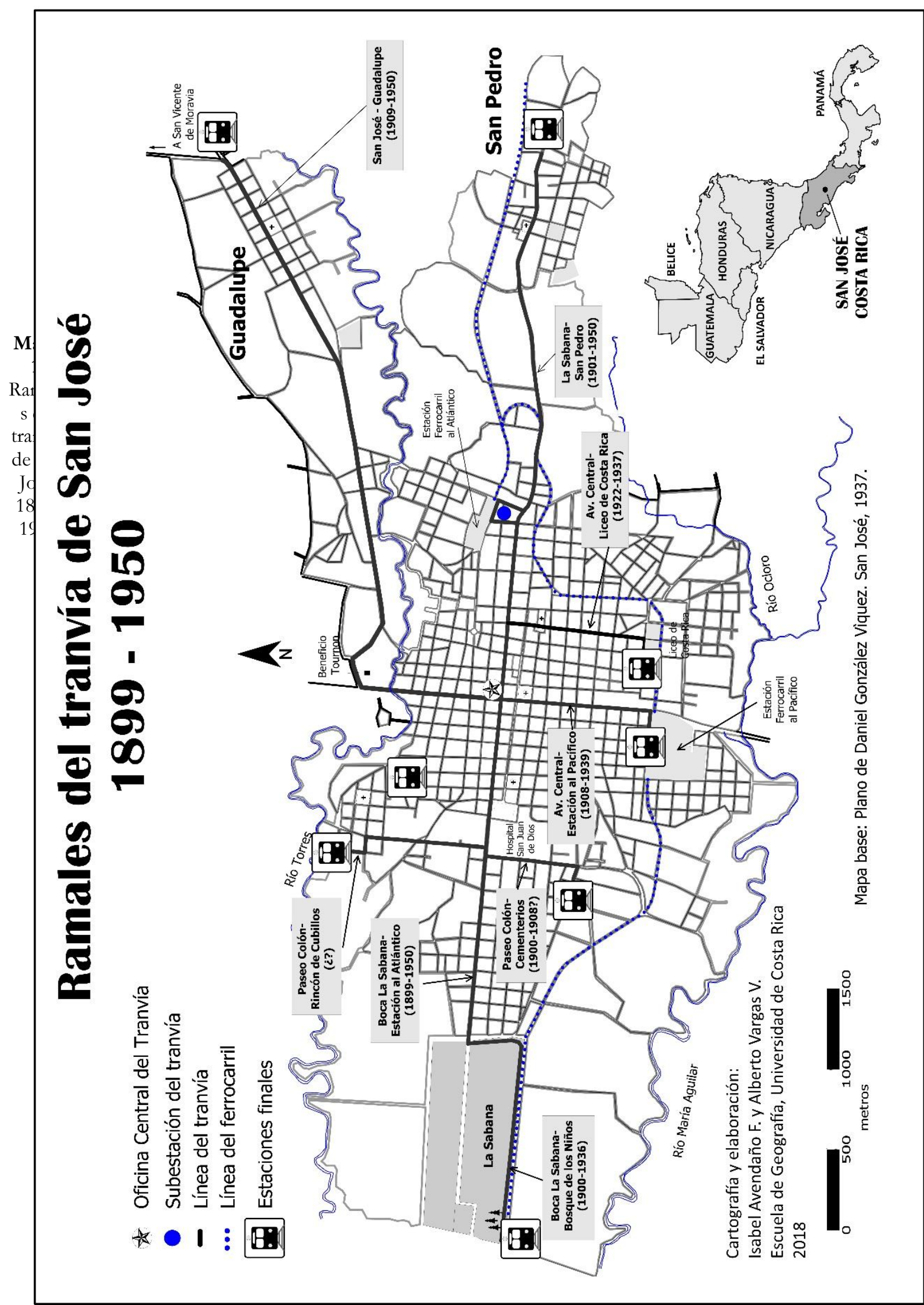


Imposible menospreciar, sus acciones en el ferrocarril o las 8.800 hectáreas denunciadas para explotación de oro en Abangares o, las extensas propiedades que tuvo derecho a poseer por la infraestructura que concretaba. Logra cristalizar un proyecto, con un combustible innovador para la época como fue la electricidad.

3. Un medio articulador del espacio urbano y constructor de signos $e$ imágenes

La incorporación de la electricidad al equipamiento urbano, reviste particular importancia porque permitió la modernización de los servicios públicos y privados, y las innovaciones tecnológicas que cubrían casi todos los campos del quehacer social, económico, cultural y político. Y poco a poco se van construyendo los mecanismos de control para transmitir significados que reproducen su poder, tales como el telégrafo, el teléfono y el tranvía. El cronista costarricense Francisco María Núñez escribió en 1941:

[...] porque la luz abuyenta hasta las cosas malas... Después del toque de ánimas casi nadie se atrevía a transitar por las callejas, por temor al Cadejos, la Llorona, la Segua... pero en las poblaciones mayores habia que celar el orden y para eso precisaba iluminar las calles céntricas, por lo menos [...7. (Núñez, 1941, como citado en Zeledón, 1994, p. 61).

A finales del siglo XIX, la Ciudad lucía una arquitectura típicamente colonial. El viajero que llegaba podía observar una construcción baja en altura, con un máximo de dos niveles, predominantemente casas de adobe y de calles empedradas. Las construcciones más antiguas eran de madera, techo de paja y paredes de adobe, que con el tiempo serían paulatinamente sustituidas por el bahareque y el uso del ladrillo. Este último material, se utilizó, sobre todo, en los edificios públicos. Naturalmente que destacan en la ciudad importantes edificios de carácter gubernamental y religioso, así como establecimientos de enseñanza, que constituyen la "obra mayor que el nuevo siglo hereda como patrimonio notable de la República y que no siempre sabrá conservar" (Bustamante, 1996), pero que aún hoy son ejes de la historia de Costa Rica y la presencia del tranvía en la ciudad de San José. Esa incapacidad de la que habla Bustamante en su texto, es importante para entender, también, la huella que dejó M. Keith en Costa Rica. También permite ubicar el inicio de un giro histórico, relacionado con el capital extranjero y la concentración, además de capitales, de territorio de las producciones de la United Fruit
Company en la región. "Articular históricamente el pasado no significa conocerlo como verdaderamente ha sido... significa apoderarse de un recuerdo tal como éste relampaguea en un instante de peligro" (Benjamin, 1999, 45).

Para esta época, la ciudad iniciaba un proceso de equipamiento urbano sin precedentes, al tenor del crecimiento poblacional, crecían las ciudades del Valle Central. La ciudad de San José en particular, multiplicaba su actividad y modificaba su paisaje. La preferencia del mercado mundial por los países productores de materias primas estimuló el cambio de las grandes ciudades, repercutiendo particularmente sobre aquellas capitales y puertos que concentraban y orientaban la producción de mayor demanda en el mercado internacional.

Los edificios como objetos sociales (Markus, 1987) transmiten significados para la sociedad relacionados con las asimetrías del poder. La Ciudad llegó a fin de siglo acusando cambios importantes en su estructura física, política y social, como resultado del desarrollo de la economía agro exportadora del país, así como, de la asunción de nuevas funciones por parte del estado costarricense. En 1889, la Municipalidad acordó la realización del primer plano oficial de la Ciudad, el que con lujo de detalles daba cuenta de cada casa, solar y dueño. Esta preocupación es fundamental y demuestra el deseo de conocer el territorio que se administraba. Hasta esa fecha lo que se tenían eran bocetos, dibujos realizados por viajeros $u$ ocasionalmente, hechos con fines didácticos.

Dos funciones más pueden agregarse al tranvía, en dos ámbitos de escala diferentes. Surgió como un medio articulador interno de la capital. Asimismo, fomentó y consolidó a San José como la cabecera económica, industrial, financiera y poblacional del país. En este sentido, este proyecto de los liberales costarricenses, constituyó un apoyo ideológico efectivo para convocar al colectivo de pobladores de San José y alrededores, en torno a una imagen de ciudad y de pertenencia.

San José dio el paso de un poblado para convertirse en "ciudad". En donde, en cada negociación entre las empresas y el gobierno siempre se tocó el tema del embellecimiento y engrandecimiento de la ciudad, así como, su necesidad y conveniencia pública (ANCR, Serie Gobernación, 4437, p. 12). Por supuesto, los medios de comunicación masivos (radio y escritos), jugaron una función respetable como formadores de opinión pública apoyando y desautorizando ideas y acciones. Para conglomerados pequeños como Guadalupe y San Pedro, el encadenamiento de dos poblados "aislados" significaba que la mancha urbana había crecido y que, desde ese momento, formaban parte de una comunidad 
mayor. Obviamente, a lo interno de San José también unía vecindarios y propiciaba la formación de otros. De forma tal que signos e imágenes se construyeron en la ciudad merced del tranvía. San José crecía, se modernizaba, generaba arraigo y sentido de pertenencia bajo un sistema racionalizado y automatizado de producción masiva y de consumo de bienes materiales (Harvey, 1998).

Los cuatro puntos del llamado casco antiguo de la Capital quedaron integrados. Los efectos espaciales se encaminaron hacia una mancha urbana que empezaba a empequeñecerse, pero también, a dinamizarse. El tranvía entrelazó lugares y creó la Ciudad a través de las actividades y los movimientos pendulares. El entramado de las sendas dio forma al territorio, imprimiendo una fisonomía espacial que se mantiene aún y articulando ejes de máximo ajetreo -ya solo esto, denota lo citadino. El tranvía marcó e inscribió el paisaje, de tal forma que oficializó un territorio diseñado por las instituciones, mucho antes de que el ciudadano, lo concibiera a su manera.

Durante el tiempo de trámites, se prohibió que el recorrido pasara por la avenida central y la avenida quinta, pero, ante la objeción de los comerciantes, la ruta se estableció por la avenida Central. La quinta se dejó como espacio público. En un inicio, Keith propuso doble vía, pero fue objetado por lo oneroso y porque, el cimbre de las máquinas aparejado al material de las viviendas socavaba el terreno, por tanto, se optó por una sola vía con bahías de cambio (switchs), que permitían que un tranvía esperara mientras el otro pasaba. Quizás, de haberse seguido la propuesta original de Keith, el tranvía hubiera pervivido unos años más, ya que uno de los criterios del desmantelamiento y eliminación de la línea tranviaria era su conversión a un medio obsoleto, lento y obstaculizador del libre y creciente tránsito vehicular. La espera en estas bahías para que el tranvía en sentido contrario pasara, molestaba a los usuarios pues perdían hasta 20 minutos.

San José se diferenciaba respecto a otras ciudades a lo interno de Costa Rica, definiéndose o tomando posición como la capital, como el nudo, el corazón del país, los más avanzados, los mejores. Por supuesto, al principio hubo resistencia y negación a lo desconocido. Las personas seguían desplazándose por los medios convencionales carreta, a acaballo o a pie- por miedo a la máquina pero también por economía, pues la novedad traía consigo un costo. El historiador, Steven Palmer argumenta que, con el ferrocarril, el país transitaba a su etapa adulta. Cabe perfectamente, la analogía de la ciudad y el tranvía. La Capital entraba a una nueva fase de crecimiento pues el tranvía fue un poderoso instrumento nacionalista como también, capitalista $y$, de reproducción de la riqueza económica y cultural.

\section{Integración social, sentido de pertenencia y distinción social: "el centro sujeta"}

El tranvía es una manera de contar la historia. La transformación social que generó el tranvía, se plasmó en varios niveles escalares: nacional, empresarial, regional y local. Un sinnúmero de ejemplos materializa esta transformación y uno de ellos, se ve en los rituales en que hombres y mujeres de todas las edades se involucraban desde la primera llegada de los carros a las diferentes localidades. Era un gran acontecimiento. A "Guadalupe", decía la banderola, y en un día de octubre de intensa radiación solar, llegaron dos vagones sonando la campanilla. Viajaba el entonces presidente Cleto González Víquez, con su comitiva, la banda militar e invitados y, le rodeaban curiosos llegados de Coronado, Sabanilla, Moravia y varias partes del cantón Goicoechea.

Cuando el tranvía llegó por primera vez a Mojón (hoy San Pedro de Montes de Oca), el pueblo festejó con un "turno". Ese domingo de agosto de 1901, a pleno medio día y con el acompañamiento de la banda militar, el expresidente Iglesias aprovechó visitar a los mojoneses, como se les solía llamar, habida cuentas, las marcas de la distinción social se concretaban en un ambiente por la adquisición de signos de prestigio; donde hecho e imaginación se estaban fusionando inevitablemente (Harvey, 1998). Se cuenta que:

Durante todo el día, especialmente después de las once, el movimiento de pasajeros en la nueva línea eléctrica fue extraordinariamente grande. Los carros que traficaban eran insuficientes para llevar aquel número de touristas de modo que cada cual se acomodaba ó se colgaba del carro como Dios o sus vecinos le permitían. No bubo, felizmente, la menor desgracia que lamentar. El servicio de los carros fue esmerado, aunque el número resultó escaso por la circunstancia indicada.

Todo el día, a pesar del agua, bubo entusiasmo en el pueblo. A veces traduciase ese entusiasmo en ligeros altercados, los que terminaban sin pasar á cosa mayor, merced a la oportuna intervención de los amigos. $\mathrm{Ha}$ sido, pues, más que satisfactoria, muy buena la inauguración del tranvía eléctrico al importante pueblo de San Pedro, que significa para éste una gran mejora, lo mismo que para San José. [sic]. (La República, 1901).

El sentido de pertenencia, está ligado al grupo de personas que trabajaba con el tranvía. El 
tranvía fue instrumento de distinción social y espacial, demarcación de la condición social, y por ende, territorial. Según las referencias escritas y orales, cualquier puesto con ligamen tranviario era prestigioso. Había un reglamento, que su puesta en práctica, generaba un "sentido de pertenecer", el cual normaba el servicio de cada máquina, con su respectiva jerarquía de mando y responsabilidades.

La comunidad josefina irradiaba aires del ser "citadino del país", como oposición a lo rural, con capacidad de diferenciar socialmente la ciudad. Este sentimiento ha sido categorizado por algunos autores con el término de "nacionalismo urbano"; sin negar las formas individuales y colectivas de la vida en la ciudad conllevando entre otros, al fomento y dinamización de las actividades comerciales y financieras.

Esos puntos de encuentros y desencuentros en que se convirtieron las estaciones finales, pronto adquirieron tal dinamismo que, en el caso de "La Estación" en Guadalupe, se le ha clasificado como el centro de mayor actividad comercial del distrito y posiblemente, del cantón. En otras palabras, resulta interesante recalcar que la intensa actividad e intercambio económico no se daba en el centro -cabecera del cantón, con cierta jerarquía político-administrativa y uno de los más poblados de los alrededores del San José de antes del decenio de 1950-, sino en las paradas finales del tranvía.

Carnicerías, zapaterías, salones de billar, barberías, panaderías y jabonerías, entre otros se encontraban en La Estación, así como, caballerizas donde las personas se cambiaban de ropa y se podían bañar. Una lectura de esta cotidianidad puede verse simbólicamente, como un despojarse del ligamen campo y vestirse de ciudad, o viceversa.

En la parada final cerca de la Plaza González Víquez, comenta Castro que allí se iniciaba una larga fila de carretas rumbo a Desamparados, unas con leña, frijoles, maíz y dulce entre otros, que habían procedido de Desamparados, Aserrí, San Miguel, Higuito, Tarbaca y del valle de Los Santos y que a su retorno llevaban productos diversos. Al lado donde hoy se encuentra la ferretería El Pipiolo, existía una caballeriza que también aparcaba coches; con volantas y cuadras para los caballos y al fondo podía encontrarse el yunque y la fragua. Servicio que era ocupado por los viajeros que venían a San José. El centro de suministros se formó alrededor de Los Mercaditos además de que existían otros establecimientos comerciales aledaños que proveían verduras, frutas, carnes, tortillas, granos (Castro, 1998).

\section{E1 tranvía forja una imagen distintiva de la Ciudad con "gente adecuada"}

Sin duda alguna, el tranvía sirvió de canal de comunicación e intercambio personal pero también, fue un medio para el ejercicio del control y la dominación social. La conformación de la ciudad junto con estos desarrollos son estructuras simbólicas que forman parte de un discurso ideológico que legitima un estilo de vida y un tipo de sociedad en particular, representan una visión de mundo particular y por tanto un tipo de sociedad, socializó e inculcó creencias, sistemas de valores y formas de comportamiento. El uso del uniforme por parte de los funcionarios a cargo de la máquina es un ejemplo que da parte, del sistema de valores y de comportamiento inculcado y heredado del "troley". La vestidura de los trabajadores en los vehículos -quepis, camisa blanca, corbata, pantalón kakis, el sello plateado de Costa Rica-, advierte que la impronta extranjera se hacía notar; con ello, favorecía un "ser distinto a otro (s)".

Otro ejemplo notable en la producción de lugares, fue la puesta en práctica del reglamento de higiene dentro de los carros; también, de una u otra forma fue la búsqueda de un "ser" con unos y frente a otros. En el reglamento oficial de 1905, se estipulaba que los conductores y motoristas debían ser personas de buenas maneras, mayores de 21 años, y tratar a los pasajeros con cortesía, así como, prestar auxilio a los ancianos y mujeres. Los objetos que se encontraran abandonados en los carros se depositaban en la Oficina Central y al parecer, este punto del reglamento se practicó, dada la cantidad de referencias orales al respecto.

Por su parte, los carros debían tener el más escrupuloso estado de aseo, se prohibía proferir palabras indecorosas o molestar a los demás; así como, discusiones en vOz alta de cualquier género. El espacio del cuerpo, siguiendo las palabras de Foucault, se mostraba el estado social que se quería marcar; es allí donde se ejercieron las fuerzas de la represión, la socialización, la disciplina y el castigo pues tampoco se permitía el fumado y dado lo usual del mascado de tabaco, se prohibía escupir en el interior del vagón salvo en las "escupideras" de porcelana, para tal acción. Lamentablemente la buena práctica se perdió, pero también, era prohibido arrojar basuras. Del mismo modo, llevar bultos molestos para los demás o que impidieran el uso de los asientos y cargar con sustancias explosivas, inflamables o mal olientes. Debían usar otro medio de transporte que no fuera el tranvía tanto las personas ebrias, desaseadas o enfermas cuyo aspecto causara desagrado o recelo, como los perros u otros animales que ocasionaran daño o mala impresión. El desacato a cualquiera de estas normas implicaba la búsqueda de otro transporte, o 
bien, caminar. Había que subir con zapatos, en un país de gente, en su mayoría, descalza. Parafraseando a Foucault (1999), el tranvía fue un espacio de represión organizada.

Una posición crítica, desmitificaría el romanticismo de una ciudad tranquila y organizada. La cultura jerarquizante que se fue desarrollando definió las contradicciones de la sociedad en la primera mitad del siglo XX, que, según palabras de Renato Ortiz (1998), el territorio es un conjunto de planos atravesados por procesos sociales diferenciados. Además, nos expresa que hay historias particulares, realidades que no se articulan necesariamente con otras historias aun cuando están inmersas en el mismo territorio nacional. Hay una aparente desconexión entre las partes que lo componen. La modernidad-mundo se caracteriza por eso, ser simultáneamente, una tendencia de conjunción y de disyunción de territorios. Se vuelca hacia dos direcciones: lo singular y la diversidad. Esta sensación de bifurcación de sentidos ha llevado a imaginarlos como vectores antagónicos, pero, sincrónicamente, son partes de un mismo fenómeno. En esta línea, Ortiz advierte de la necesidad de evitar la ingenuidad de que un territorio como el de la ciudad no esté estructurado a partir de determinadas relaciones de poder o líneas de fuerza con peso y legitimidades distintas.

\section{Mutaciones en el ritmo trastocan el territorio}

Del mismo modo en que cambió lo espacial del San José de finales del siglo XIX, también la vivencia temporal varió. El uso del tranvía se convirtió en una tradición que consolidó la concepción del tiempo como un recurso limitado, con valor y escaso. El vehículo acortaba el ritmo de desplazamiento dentro y alrededores de la Ciudad, agilizaba la vida y disciplinaba al usuario en virtud de los horarios de ida y vuelta. Algunos de los conductores y maquinistas argumentan que los itinerarios eran sumamente estrictos, expresando con esto una forma de actuar de una administración que estaba liderada por europeos y estadounidenses.

Desde 1905, se estableció en el Reglamento que, al terminar las bocacalles, los carros se detendrían para subir o bajar pasajeros. En consonancia con la cultura costarricense, el modelo importado se reterritorializó. El lugar de ingresar o descender del tranvía se convirtió en una práctica informal a merced de una acción más libre, espontánea y que seguía las necesidades de los usuarios de un San José, que el mismo tranvía contribuía a empequeñecer.

Francisco Amighetti fue uno de los pocos autores que hicieron descripciones de un San José de esos tiempos. Aunque breves, las alusiones de un "nosotros" frente a lo "otro" permiten una reconstrucción de aquel medio de transporte. Así, se expresa de Buenos Aires y San José en 1931 y entrelíneas argumenta:

En algunas esquinas el tránsito alcanzaba proporciones de sonora catástrofe con sus tranvías desbocados. En Costa Rica eran pequeños e iban chirriando hacia el poniente [los tranvias], en mi ciudad rodeada de montañas... Cuando San José era una capital de sesenta mil habitantes, bastaba llamar desde lejos para detener el tranvía, y aún los trenes, sin que mediaran por eso accidentes ferroviarios... En aquel puerto a orillas del río, las mujeres que tomaban el ómnibus corrian y se empujaban, hombres o mujeres. Todos eran enemigos en aquel momento. (Amighetti, 1993, p. 39).

Inevitablemente, un medio de transporte innovador con el sistema tranviario permitió ser utilizado para la diversión y el entretenimiento para usuarios y funcionarios. Cuenta doña Dulce (Comunicación personal, marzo 2003) que ella vivía en Tierra Blanca de Cartago, estando en la escuela hacia 1949, a la maestra se le ocurrió traer a sus alumnos a San José para que conocieran el "Parque Bolívar" y el balneario Los Juncales. En ese momento conoció al famoso tranvía; un recuerdo entrañable nos cuenta. De tal manera, solo el hecho de subir e interactuar con aquella máquina representante de la modernidad y la modernización, constituía para muchas personas, un acontecimiento inolvidable. Nos dice Harvey (1998, p. 25), ser "modernos es estar en un medio que promete aventura, poder, goce, crecimiento, transformación de nosotros mismos y el mundo. Y, al mismo tiempo, que amenaza destruir lo que tenemos, todo lo que sabemos, todo lo que somos".

El periodista Fernández de La República, escribió en 1978, que su excursión preferida era a la pequeña población de Guadalupe. Una de las razones del encanto por viajar a ese lugar era el tranvía. También, recuerda el motorista Cayetano Porras (Peña, 1999, p. 75) que rumbo a Guadalupe, se localizaba la finca y el beneficio Tournon: “... en aquel tiempo ellos tenían un estanque muy grande donde habitaban patos, carracos y había una vegetación muy linda, creo que era un lugar muy atractivo para las personas que por ahí viajaban...". (La República, 1978).

Los medios y experiencias modernos atraviesan todas las fronteras geográficas y étnicas, de clase y nacionalidad, religiosas e ideológicas expresa Harvey (1998). El tranvía modificó el lenguaje cotidiano, algunos términos sufrieron transculturación: trolear, encarrilarse, descarrilarse; expresiones como: "como caldo de riel"; "la dejó el 
tren"; "más larga que miada en tren" o "echar carbón", son solo algunas de las expresiones de herencia de la tecnología ferrocarrilera y con ella, tranviaria. Dice Silva (1998) que una forma de apropiarse del territorio o de los objetos, es nombrar y renombrar, es un característico ejercicio existencial-lingüístico: aquello que vivo lo nombro; sutiles y fecundas estrategias del lenguaje.

Dado que el tranvía y la electricidad van de la mano, permitió que la gente adquiriera otros servicios complementarios, los cuales en definitiva facilitaban el desarrollo de los lugares por donde corría este medio. Tal es el caso de lámparas incandescentes y de arco, cocinas, calentadores, planchas y aparatos para cine y para rayos " $\mathrm{X}$ " (Núñez, 1924, p. 116).

\section{Una obra de lucro para los "extranjeros"}

Tanto el tranvía como el ferrocarril fueron obras con creciente control extranjero y no todas sus huellas se borran en el objeto. Por una parte, influyó el origen del capital, que en forma de empréstitos y acciones se manipuló y hasta burló al Estado costarricense. La cabeza de la administración, siempre es mencionada en las actas municipales con gran reverencia, no así con otros grupos de extranjeros. Y por otra parte, había una organización jerárquica sumamente rígida, propia de ciudades administrativas de enclave, que hace patente la conformación de estratos verticales inaccesible, incluso, para algún costarricense no importa su estrato social. De una u otra forma, la empresa fomentó una percepción hacia los migrantes que se ha perpetuado y en la cual, se diferencia entre el ser extranjero y ser inmigrante. Los estadounidenses, ingleses, alemanes o españoles eran los extranjeros ubicados en la cúspide de la pirámide social, constituían la mano de obra especializada, difundían los conocimientos más innovadores, irremplazables puesto que constituían los maestros de los costarricenses. Va conformando un paralelismo con la cultura del ser costarricense, con escenarios de dominación claramente identificables en la ciudad y más evidente en la primera mitad del siglo XX en los enclaves bananeros.

Trabajar y residir a Costa Rica debía considerar incentivos llamativos -lucrativos-. En las actas municipales, se discutían los salarios de los trabajadores de la Compañía que ganaban salarios "escandalosos", solamente comparables con los de los altos funcionarios gubernamentales. Aún para los extranjeros que venían como mecánicos, los salarios eran superiores a los de un costarricense en las mismas condiciones.
Dentro de los beneficios a un grupo social estuvo vigente el lucro de los extranjeros. La concesión de la red tranviaria permitía el "tanteo" lo que económicamente era poco rentable caía en desuso-; pero también la concesión de pajas de agua e instalación de las plantas de fuerza para la generación motriz en los ríos Tiribí y María Aguilar; declarar libre de derechos fiscales la entrada de materiales para la construcción, mantenimiento y conservación del tranvía como máquinas, muebles, semovientes, etc.; expropiar todo aquel lugar que los empresarios quisieran y que consideraran indispensables. Aunque no tuvo frutos, Keith luchó para que se le pagara en moneda de oro -moneda imaginaria decían los regidores municipales, a la cual se le quería aplicar devaluación y cambio a libras esterlinas-.

El carácter monopólico se acrecentó hasta permear el corazón del país. Las innumerables peticiones y exigencias confirman la lógica capitalista y transnacional. Tampoco fue tan fácil la instalación. Seguridad, desconfianza o control estatal en cada concesión fue, según puño y letra de Minor Keith dirigiéndose al Ministro de Gobernación, una odisea. El fragmento siguiente es una fotografía de la historia construida desde los vencedores (Benjamin, 1999), marcada por un modelo de desarrollo exógeno, a saber:

[...] Presenté á la Municipalidad el plano y trazado del tranvía y le pedi autorización para empezar los trabajos de la via; pero aquella Corporación [la Municipalidad de San José', con fútiles pretextos, demoró y demora aún sin resolución.

Tengo en el país casi todos los materiales del tranvía... se activan los trabajos de instalación de los aparatos eléctricos y no se han terminado en su mayor parte, debido á las dificultades que ha puesto la Municipalidad.

Después de haber gastado más de cuarenta mil pesos en alistar el material del tranvía justo es que yo me resista á pasar por la decisión inconsulta de la Municipalidad [...]. (ANCR, Serie Gobernación, 1891, p. 2).

\section{Un patrimonio nulo en la memoria histórica josefina}

Argumenta Sandoval (1997) que las prácticas cotidianas, aquellas del día tras día en nuestro pasar por la vida, nos parecen tan obvias, pero tan obvias, que nunca nos cuestionamos por ellas. El medio de transporte tranviario fue una forma casi imperceptible que pasó al plano de lo 'natural' porque si se hace una revisión de la literatura costarricense de la primera mitad del siglo $\mathrm{XX}$, es fácil percatarse de las escasas alusiones al tranvía. Nadie se dedica a estudiar el impacto o los efectos económicos, sociales o culturales implícitos 
y explícitos.

En las obras de Joaquín García Monge en "El Moto" como para Carmen Lyra, el tranvía era un ruido a la distancia; siempre en segundo plano; para Luisa González en "A ras del suelo" fue ese medio que la llevó con sus enaguas amarillas a su primer día de clase como maestra. Carlos Luis Fallas y Fabián Dobles se dedicaron al campesino y de la pobreza. El fabuloso Magón que cuenta agradables historias de ese San José con tranvía, si acaso lo menciona alguna vez. De alguna forma estas obras reflejan que el tranvía fue parte de la rutina cotidiana; no era tema de discusión ni de atención. Constituyó una vivencia del día a día, una aprehensión diaria para una importante cantidad de personas y se esperaría que hubiese sido el fundamento desde el cual surge el sentido, pero dado que el proceso es poco nítido queda claro que no todos los actos repetitivos se transforman en sentido ni son socialmente procesados.

Los pintores costarricenses de las primeras décadas del siglo XX, se inspiraron en el universo rural, en ese rural idílico que persiste en la actualidad. La casa de adobes y su techo de teja fue uno de los componentes esenciales y recurrentes en las obras de arte. Tanto en la pintura como en la literatura, tal parece, que hubo un despojo de los elementos considerados "modernos", aquellos que en las zonas rurales representaban el avance, el progreso o la distinción. La preocupación por recuperar una edad de oro perdida, destaca en los lienzos, así como, escapar del universo urbano que les desagradaba por la creciente visualización de la pobreza, agravada por la crisis de 1930 (Molina, 2002). Quizás aquí exista una razón del por qué el tranvía nunca ocupó un lugar central en la cultura urbana escrita ni en la obra artística. Este borroso tratamiento o segundo plano ha impedido que futuras generaciones conocieran una forma más del modus vivendi cotidiano, de los intercambios personales, de la impronta en el territorio y de la vida del día a día tanto de ese medio de transporte como del otrora, San José.

La vida vehicular llegó para quedarse, transformando la cultura en general desde las formas de lenguaje cotidiano hasta las formas salvajes de comportamiento en las carreteras. Presiones e intereses de quienes abanderaban la ola expansiva de la flota vehicular fueron borrando al tranvía hasta su desaparición dentro del imaginario. La única máquina existente, que, dicho sea de paso, no es original sino una reconstrucción o rompecabezas, se localiza en el Parque de Diversiones en el distrito Uruca, cantón San José.

Ciertamente, la máquina se mantiene en buen estado. Sin embargo, como su nombre lo dice, el Parque de Diversiones es un lugar de entretenimiento, ocio y recreación. El vehículo bajo techo, está rodeado de muchas opciones para las distracciones. Además, la localización dentro la mancha urbana josefina del Parque, impide la interacción cotidiana y de darse alguna curiosidad por parte de algún visitante, tendrá un carácter esporádico. Al tranvía se le ha sustraído su historia, legado y contexto; se le ha sido vaciado de contenido; del cómo y del por qué surgió. Su sentido intrínseco ha sido congelado; es un producto inerte que poco evoca en el observador en el caso de que una mirada le enfoque. Canclini (1989) se refiere a los monumentos de las ciudades como aquellos objetos que interactúan con el cambio. Pero con el tranvía, ni siquiera está inmerso en el proceso dinámico de la ciudad. Ha sido desterritorializado; literalmente enterrado. Hoy es un fantasma en el territorio nacional, inexistente en el medio "natural" que le vio nacer, crecer y desaparecer.

\section{A manera de conclusión}

De acuerdo con Harvey (1998), la modernidad no solo supone una violenta ruptura con alguna o con todas las condiciones históricas precedentes, sino que se caracteriza por un proceso interminable de rupturas y fragmentaciones internas. Para Ballesteros, funcionario de la empresa tranviaria (Minsky, 1991), durante mucho tiempo el tranvía contó con la preferencia de los usuarios, pese a que ya circulaban algunos autobuses como los "Los Plateados", que eran más veloces y cobraban la misma tarifa. A tres meses del cierre del tranvía, en respuesta a un aumento de la tarifa de autobuses, los vecinos de San Pedro y Guadalupe solicitaron a las respectivas municipalidades el restablecimiento del servicio (La Prensa Libre, 1950). Sin embargo, nunca más fue restaurado. En este punto, podemos hablar que el medio pasó de una condición de modernidad a uno de la posmodernidad en donde lo efímero y el contrato temporario en todo, se convierte en el signo de la vida posmoderna (Harvey, 1998).

Bustamante (1996) argumenta que la compañía obtenía ganancias insuficientes por el rendimiento del medio de transporte. Por ello, negoció con el gobierno para cerrar el contrato. Dio al ICE la suma de 1.700 .000 colones e implementos eléctricos por un valor aparentemente superior a los 300000 colones “... es uno de los pocos casos en que una compañía paga para dar fin a sus obligaciones; en todas partes es por lo general el gobierno el que indemniza... pero en Costa Rica hubo una excepción".

La cultura vehicular bajo la máscara, también, del progreso y el bienestar provocó un desprecio hasta el punto de su eliminación (junto a 
un servicio deteriorado). Faltó visión y conciencia crítica, no se trataba de cerrarse al mundo ni de excluir, pero sí tener la capacidad de tamizar aquellas cosas que nos vienen de una tecnología más avanzada. Faltó valorar la nueva geografía pública de la ciudad y lo positivo del tranvía, vehículo que poco a poco fue incorporándose a nuestra cultura popular rica en expresiones. Se impidió reinventar al tranvía como una nueva forma de espacio interactivo, de jugar con las posibilidades tecnológicas, de innovar y modernizar, sencillamente se desechó, en lugar de capitalizar esas formas tempranas de modernización material de la ciudad, ligados también a los espacios políticos republicanos y al sistema político liberal que predomina entre el último tercio del siglo XIX y la primera mitad del siglo XX.

Ese patrimonio cultural, la afectividad, el intercambio de personas, la socialización y la convivencia social rotundamente, son irrecuperables. Mas, como patrimonio también ha sido olvidado. En cincuenta años de tránsito continuo, dejó rasgos en la cultura; evoca identificación en el espectador; por ello, hablamos de un patrimonio cultural que ha caído en el olvido pero que hay que rescatar en nuestras nuevas generaciones. Debemos interiorizar la idea de que el tranvía debe ser parte del acervo material con el que cuenta el país e incluso, debiera ser mencionado en el sistema educativo. Fue un medio que ayudó a configurar el sentido, el sentido del ser josefino. Un artefacto que encarnó experiencias y actividades, recuerdos de acontecimientos significativos de la vida y de la gente.

Aún se está a tiempo de despertar la curiosidad de todos sobre este patrimonio que como un fantasma recorre la ciudad y, aunque no calza en las definiciones de la UNESCO como Patrimonio mundial, los principios que ese organismo plantea de identificar, proteger, conservar y señalizar, para los habitantes y los visitantes, por ser un elemento representativo de una época, es un bien que debe ser rescatado; esta propuesta plantea un reto intelectual, metodológico y político, para diferenciarlo en su especificidad, y lograr la materialización de estas pequeñas partes que sobreviven en el paisaje de lo que fue la ciudad. Su visibilización servirá como una herramienta para generar conciencia, para generar información y para comprender los valores que han contribuido a forjar la nacionalidad del costarricense.

\section{Referencias bibliográficas}

Amighetti, F. (1993). Obra literaria. San José: Editorial de la Universidad de Costa Rica.

Archivo Nacional de Costa Rica (ANCR) (1920). Serie Congreso, Serie Gobernación. San José.

Avendaño-Flores, I. (1991). El tranvía y su Amighetti a la formación de la población de Guadalupe. Revista Herencia, 3 (1 y 2).

Avendaño-Flores, I. (2003). Abordando el tranvía de San José: Un patrimonio cultural en olvido. Revista Herencia, 15 (2).

Barzuna, G. (1989). Caserón de teja: Ensayos sobre patrimonio y cultura popular en Costa Rica. San José: Editorial Nueva Década.

Benjamin, W. (1999). Tesis sobre el concepto de la historia. Ensayos escogidos. México: Ediciones Coyoacán.

Bustamante G., T. (1996). La ciudad de San José. Ensayo Histórico. Municipalidad de San José. San José.

Castro D., W. (1998). Barrio Plaza Viquez: In E. O. García \& F. J. E. Solano. Historias de mi barrio (el San José de ayer). San José: Editorial Costa Rica.

Dirección General de Estadística y Censos (DGEC). 1892, 1927, 1950. Censos de población. San José.

Emmerich, N. (2011). La memoria bistórica: derrota, resistencia y reconstrucción del pasado. pp. 1-17. Recuperado http://www.izt.uam.mx/mydes/document os/memoria $\% 20$ historica.pdf

Fernández, M. (1978). Excursión a Guadalupe. La Prensa Libre. 9 noviembre, p.12.

Foucault, M. (1999). Estrategias de poder. Paidós: Barcelona.

Canclini, N. G. (1989). Culturas hibridas. Estrategias para entrar y salir de la modernidad. Estrategias para entrar y salir de la modernidad. México: Editorial Grijalbo S.A.

Harvey, D. (1998). La condición de la posmodernidad. Investigación sobre los orígenes del cambio cultural. Buenos Aires: Amorrortu Editores.

Huertas, V. (1959). A los 50 años de la inanguración del tranvía de Guadalupe. La República. 11 octubre, p.2.

La Prensa Libre (1993, 27 de junio). Servicio de tranvias. p. 6.

La Prensa Libre ( 1978, 7 de diciembre). Breve desarrollo histórico del cantón de Guadalupe (sic). p.2.

La Prensa Libre. (1950, 9 de noviembre), p.4.

La República. (1991, 20 de agosto). El tranvía a San Pedro. El señor presidente en el pueblo. La fiesta. San José.

Markus, T. (1987). Buildings as classiffing devices. 
Environment and Planning (Vol. 14). Scotland.

Minsky, L. (1991). Recuerdos sobre rieles. La Nación, pp. 8c y 10c, abril.

Molina, I. (2002). Costarricense por dicha: Identidad nacional y cambio cultural en Costa Rica durante los siglos XIX y XX. San José: Editorial de la Universidad de Costa Rica.

Morrison, A. (2008, 2 de agosto). The Tramways of Costa Rica Puntarenas, Cartago, San José, Guácimo. Recuperado de http://www.tramz.com/cr/cr.html

Municipalidad de San José. (1920). Contratos sobre tranvía, alumbrado, rentas y créditos, cañería y cloacas. San José: Imprenta Lehmnann.

Núñez M., F. M. (1924). Iniciación y desarrollo de las vias de comunicación y empresas de transportes en Costa Rica. San José: Imprenta Nacional.

Ortiz, R. (1998). Otro territorio. Santafé de Bogotá: Convenio Anfrés Bello.

Peña, O. S. (1999). Viajando sobre los rieles en Costa Rica: El tranvía. San José: Sandy.

Silva, A. (1998). Imaginarios urbanos. Cultura y comunicación urbana. Santafé de Bogotá: Tercer Mundo Editores.

UNESCO (2011). Conferencia General de la UNESCO: Historic Urban Landscape was adopted on 10 November 2011.

Zeledón C., E. (1994). Imágenes costarricenses. Crónicas de Francisco María Núnez, José J. Sánchezy José Antonio Zavaleta. San José: Editorial de la Universidad de Costa Rica.

\section{Cómo citar este artículo}

Avendaño-Flores, M. I. (2018). El tranvía de San José: un fantasma de la memoria histórica urbana y del patrimonio de Costa Rica. PatryTer, (1), 1, pp. 44-56.

DOI: https://doi.org/10.26512/patryter.v1i1.7089 